\title{
Brueghel's Two Monkeys: Passing the Final Exam in the History of Mankind
}

\author{
Ingrid E. Newkirk \\ People for the Ethical Treatment of Animals, Norfolk, VA, USA
}

\begin{abstract}
Summary
As society's ethical values expand over time, we understand that we must have consideration for more than just ourselves, our race, our gender, and our species. This talk confronts our biases and provides food for thought in moving beyond our current understanding of human-animal relations. History provides a lens through which our current norms can be viewed. It allows us to discern how our behavior might be perceived by future generations, and this perspective can help us understand how to improve our behavior. While it is easy to be appalled by what has been done in the past, it is more challenging to uncover the actions taking place today that will be regarded with horror in the future and, most important by far, to be a part of the necessary change. By modifying one's perspective to include a more empathetic view of other animals, our obligations and potential become clear.
\end{abstract}

Keywords: animal rights, animal experimentation, non-animal testing, alternatives, empathy, fear, ethics, ICCVAM, EPA

\section{What kind of animal are we?}

When I was in school, we didn't consider the rights or protection of animals an issue. I went to a convent in the Himalayas in Kodaikanal, Southern India, and I gassed animals for dissection class without much thought. Looking out at this room, I see some of you are my age or thereabouts and so probably, like me, missed out on the animal rights and ethics courses offered in universities today. In other words, we are late in wrapping our brains around these concepts. The rest of you have no excuse!

Are most human beings inherently kind? Well, I don't have any empirical evidence that many people are unkind, but I do have a lot of anecdotal evidence that some are. And it strikes me that, on the strength of that - as with criminal law, where a collection of circumstantial evidence is allowed to win a conviction - we can pretty much characterize the human race, of which I am a living, breathing part, as being, quite often, "a species behaving badly" - especially when no one is looking.

In Amsterdam, for instance, the honor system of putting out public bicycles had to be dissolved, because so many bicycles have been stolen, repainted, and sold. And then there's the person who stole my wallet. Luckily they left the Euros and only took the dollars, which are almost worthless. But such is human nature that even friendly, well-educated people who should know better often behave badly, and I'm not just talking about hedge fund managers.

In a study of visitors to Antarctica, it was found that people with a university or postgraduate education were significantly more inclined to harass seals and trample plants than those with less formal education. And then there is "pack behavior": Abu Ghraib isn't the only place where people have engaged in conduct that would be seen as truly depraved under normal circum- stances but which became normal and routine, even amusing, as the "group mind" muted out decency.

So, average people are capable of more cruelty than we'd like to believe, sometimes not even seeing their behavior as wrong. And sometimes this cruelty becomes institutionalized and is not even seen as abnormal any more. That means, of course, that animals, elderly people, children, and any others placed in a vulnerable position or in an institution, such as an orphanage, a nursing home, or a laboratory, are far more likely to be abused.

Let me give some examples of why I say this:

Look at those who not only have taken a solemn vow to be good but who are expected to set the bar on goodness. The church is an institution more respected than any other. Yet the Roman Catholic Church, not only in the US but in Europe, has had to learn that going along with and, indeed, covering up abuse may one day catch up with you. We all know now about the little boys, and some girls, who were too scared to speak up and who had their lives and bodies interfered with. But, if pillars of the community demonstrate no regard for the feelings of children in their care, it would be mad to think that animals in laboratories, who certainly don't enjoy anything like the revered status of children in our society, are being well treated!

And no one is naïve enough to believe that research is somehow an exception - that it is the one place on earth where those in charge can be trusted to police themselves. That's like leaving a 5-year old in charge of a chocolate cake. Which, actually, researchers have done and the results are not surprising!

Let me offer some idea of what our investigators and others have found: When they thought no one who cared was looking: UNC researchers put live animals into the freezer bins and cut off rodents' heads with scissors without any effort to lessen their suffering; researchers who couldn't be bothered to walk

Plenary lecture held at the $7^{\text {th }}$ Worldcongress in Rome 2009 
to the gas chamber room chose to violate their protocols and kill the animals by breaking their necks against the cage cardholders. Technicians at Huntingdon Life Sciences in the U.K. were filmed punching beagles in the face and simulating sex with each other as they tried to inject a frightened dog at the same time. Researchers at the largest contract laboratory in the US, Covance, were caught slamming petrified monkeys into steel cages or, having tied them down to the table, stuffing bottles in their mouths and mocking them while whooping it up to loud music. Covance's reaction was not to decry the behavior and fling the abusers and their supervisors out the door, but to sue us - both in the UK and in the US - to get us to stop showing those videos. They lost their cases.

These are dismaying examples of people shamelessly abusing their power over others in their care and then trying to cover it up. And it's not just at Covance. Every single time we go into an institution undercover - including at AAALAC-accredited institutions - we come out with footage of atrocities.

Animals, like institutionalized people, are often simply forgotten; they become wallpaper. Once, I was touring the National Institute of Health (NIH) model facility in Poolesville, Maryland - a "model" facility, mind you - when I found some baboons being kept in small metal isolation cages. I found them because I was walking along one of the corridors and heard a fearful banging noise. That made me look through the little window into their room to see a huge male smashing his head into the stainless steel back wall of his cage. He was a Hamadryus baboon: huge, with a big snout like a dog, and such a colorful coat, sticking out all over, that he looked like a man who had been plucked off the street on his way to a fancy dress ball. I enquired about these baboons, each sitting in a standard, small metal isolation cage in this stark, barren room, with nothing to do or see or touch, no contact with each other, unable to even walk two steps. And I discovered that the researcher who had been using them in a cancer study had accepted another job two years earlier and had moved way! He was living his life in a new town, driving around, shopping, watching TV, talking to his kids, and the baboons were sitting there, day in and day out. They had been plucked from their homes, troupes, and families in Africa seven years earlier, shipped to Russia and then to the US on what could only have been frightening journeys for them, and then locked in see-through boxes in a room, and left to stare at the walls for seven years. Once a day, men in masks entered and hosed down the room and put food in their metal bowls.

Except for the absence of water boarding, they might as well have been at Guantanamo Bay.

Who was to blame for this casual oversight that caused these bright animals so much misery? The grant provider? The researcher who left? The technicians? The IACUC? All of the above, surely? Not one of them had thought the baboons important enough to wonder about, even those who had seen these animals every day. This kind of appalling neglect, in which a living being is left to experience needless mental strain, goes on all the time. So, we must be vigilant, each of us in a position to do so, to spot it and stop it. Otherwise, what kind of animal are we?
People in institutions often get used to things that disturb other people. They are like the lighthouse keeper who was so accustomed to hearing a gun go off under his nose, every six minutes, every night, to warn ships at sea that he slept through it. One night, the mechanism failed and the gun didn't go off. The lighthouse keeper woke with a start, sat up in bed and said, "What's that?"

We need to be vigilant to what's happening to others around us, because those over whom we have control can only depend on us to notice their circumstances. We cannot allow animals to become the wallpaper we don't see any more.

Those of you here who are striving to get animals out of research or at least treated with some understanding of who they are and what they need, have to deal with those who can't empathize (neurophysiologists can debate whether that means that their "mirror neurons" are underdeveloped or not), and with others who think it's perfectly fine to wait until some unspecified time in the future to make changes or that change is just not a priority. And we all have to deal with people on IACUCs who are untrained, don't appreciate the important responsibility vested in them, or who get too busy - personally or professionally - to take a proper look when a protocol is presented that could result in animals being put through painful, uncomfortable, and worrisome procedures that should have been modified or rejected outright. That is unconscionable.

\section{Today's conduct as future "past" horrific behavior}

It is said that the only thing we learn from history is that we don't learn from history. Let me examine with you how history applies to our behavior toward animals today.

One of the most studied cases in research ethics is, as you know, the Tuskegee experiment, in which poor black men in the southern US were purposely not told by their doctors that they had syphilis and were simply used as research subjects. This is a good example because it involves a marginalized group - individuals with no recourse, who didn't seem to count for much, and whom the dominant group did not understand or consider important. And because the researchers may indeed have had some sort of good intentions but didn't realize that, at some later point they'd be condemned for such a lack of empathy.

But it's not only the Tuskegee men. Human orphans were used in tuberculin tests and trials of low levels of radiation; poor Irish women immigrants to the US were used in gynecological practice surgeries which, when perfected, were performed on the rich, paying classes. Even human neonates were operated on without anesthesia until quite recently.

In the US, enlisted men (GIs) were used in LSD experiments without their knowledge; some thought they were going mad and killed themselves. GIs were used because they are a pool of often low-income men considered cheap, disposable, and replaceable. Sound familiar?

It is easy to be appalled by what has been done in the past, but callous behavior seen as acceptable just yesterday is now seen for what it is: ignorant and wrong. 
For truly uncomfortable reading, there is "The Nazi Doctors," by Robert J. Lifton. In his study of what made doctors able to live with themselves while doing to prisoners exactly the sorts of ghastly things that are done to animals in today's laboratories, including drowning experiments and teratogenicity experiments, he discovers that the comfortable idea that they were just "some madmen" ruled by another madman is absolutely unsupported. In fact, vast numbers of people somehow rationalized these extreme cruelties and killings in a variety of ways and not only accepted it but participated in it.

Lifton's conclusion is that these experimenters were ordinary people like us. One of them, Dr. Siegmund Rascher, even felt comfortable enough to put on paper a formal request to Berlin to move his experiments on inmates from Dachau to Auschwitz because, he wrote: "In Auschwitz, the freezing process is faster because it is colder there. Moreover, the camp is bigger, so that the subjects' howling can hardly be heard."

The analogies are clear. Nobel Laureate Isaac Bashevis Singer, whose family fled the Nazis, became a vegetarian because he looked out of his window above a slaughterhouse in Chicago, watched the cattle shackled together, being prodded and poked down the ramp to their deaths and wrote, "To animals, all men are Nazis."

Lucy Kaplan Rosen, who wrote the introduction to Eternal Treblinka, tells the story of her father, who was transported in a cattle car to Birkenau-Auschwitz in 1944. This was after he had witnessed the murder of his wife and two daughters. He survived six camps. Ms. Rosen says that what she loved most about her father was that when, in 1945, at only $100 \mathrm{lbs}$ and bearing the injuries of years of Nazi abuse, he emerged with his previous compassion for animals enhanced precisely because he realized that he had been treated like one.

So, we see that past atrocities weren't necessarily an aberration, and ordinary people can do hideous things if they don't discipline themselves not to or are not stopped by someone else.

The trick, however, is not in simply looking backwards but in figuring out what is being done today that will be looked back upon in the future with disgust. The trick is to be one of the people who finds a way to reach those who can't or won't relate to the being on their hotplate.

Lifton's study is also instructive in another way. It suggests that - if the same observations of human nature apply today of every three people hired as animal caretakers, two will not object, even silently, when an animal is abused or neglected, and one of the three will be easily capable of joining in flagrant abuse. Let's ask ourselves then, of every ten people appointed to an IACUC, how many will speak up when an unnecessary or unnecessarily cruel experiment is proposed?

On the encouraging side, we teach our children that "Might Does Not Make Right," and we ask them to obey the Golden Rule of "Do Unto Others as You Would Have Them Do Unto You." Presumably, we mean those things. But when you think about it, only "might" allows someone to pick up a rat, a mammal every bit as sentient as any dog or cat or me, and bleed him from the eye and then toss him back into a shoebox-sized container, as if the rat's experience, his fears and sensations aren't real. And only a lack of empathy would allow someone to joke that now the animal will need a white stick when he goes out on the town.

We all know that scientists want to be thought of as precise and particular. Perhaps you know the joke about two scientists driving along in Australia when they pass a flock of sheep. "Look," said one, "Those sheep have all been sheared." "Well," says the other scientist, "On one side of their bodies, anyway." Like most stereotypes, I'm not sure this business about particularity is true, and I'll tell you why:

A few years back, we ran a photo in PETA's Animal Times magazine that showed rats stuffed into narrow plastic inhalation tubes like so many socks. You can imagine how frightening it must be to have giant aliens, whose intentions are not benign, stuff you into a tube so tightly that your nose and ears are squashed against the sides. The picture was from an article published in the journal of the National Institute of Environmental Health Sciences, and the "cute" caption under the original photo read: "Nosing Around." It reminded me of a caption I saw on a photograph of a group of black males, unable to find work in a South African township, with the caption, "Lounging Around." The article in the NIEHS magazine described an experiment in which rats were forced to breathe mercury vapors in an attempt to duplicate the reproductive effects already seen for years in dental hygienists exposed to mercury in fillings. Incidentally, the Principal Investigator concluded: "We weren't able to reproduce any of those effects in our animal model."

When we showed this photo to the head of ICCVAM, he shook his head and said, "that's terrible." But it turns out he didn't mean that the experiment was terrible or what was done to the rats was terrible; he meant that it was terrible that the photo had been put in the magazine for everyone to see!

PETA researchers attend many toxicology conferences. They hear the jokes, the references to boondoggles, the acknowledgements that certain experiments have no value whatsoever. On a tour of the USUHS, the US Uniformed Health Services facility, the chief veterinarian in charge pointed to the desert tortoises being used to study TMJ (temporo mandibular joint pain). Now, the desert tortoise's jaw is not like a human jaw at all; it is especially arranged for a fibrous, plant-based diet there are no teeth! People chew their food, tortoises do not, and there are many other critical differences. Furthermore, the NIH says that TMJ treatment should not be surgical, rather it begins with simply changing jaw movement and avoiding teeth-grinding. Considering that a desert tortoise cannot be reasonably expected to speak our language, and we don't understand hers, it will be difficult to explain this to her and to know when she feels better.

PETA did a double take and got the funding on that experiment pulled. If we hadn't, who knows how many other tortoises would have had their jaws damaged and how many more tax dollars would have been wasted.

I was once invited to lecture at the USUHS and made the mistake - or clever move - of arriving early enough to sit unnoticed in the back before the earlier session ended. The laboratory chief told his students: "When you fill out the government form as to why you chose to use rats or mice, do not write 'because they are cheap, easy to handle, and few people care about them.' The form is supposed to show there is a good science-y 
sounding reason for your choice." But the truth is, there is no "science-y" reason.

At a conference on neurotoxicity, a panelist discussing the EPA's developmental neurotoxicity test (which uses at least 1,300 animals every time it is conducted) joked that the "FOB" - which is the acronym for the "functional observation battery" that is used in neurotoxicity testing - really stands for, and I quote: "functional observation bullshit." In that government scientist's words, "we do it because the EPA tells us to," regardless of relevance. In my words, "They die for our sins."

The EPA official on the panel acknowledged: "We know the rat isn't the right model. But it's like being in a bad marriage you know you should get out but you don't because there's so much history there." That would be funny, but it isn't if you are the subject of a painful experiment.

So, the gig is up on pretending that results from one species apply across the board to others. I've always said that "When it comes to feelings, like hunger, pain, and thirst, a rat is a pig is a dog is a boy." That's just a plain old fact. What isn't a fact is that when it comes to physiology, a rat is a pig is a dog is a boy. Meaning that it's time for the so-called "gold standard" of animal testing to be recognized as the lump of coal it is.

One more example of how casually the animals' suffering is viewed: Several years ago, at the National Academy of Sciences' Institute for Laboratory Animal Research workshop on federal reporting requirements for pain and distress in animals used in laboratories, panelists who included animal researchers from the US Department of Agriculture (USDA), the NIH, and various universities and professional associations, were often seen yukking it up over animal suffering. Empathy was in short supply, if there at all. One of the panelists spoke about the importance of proper training. Reciting a "can-ya-believe-this-one" story, he gave a litany of botched jobs by under-trained or under-skilled lab staff, culminating in a story of someone improperly restraining a mouse so that, as the animal's skull was being drilled into, his body spun around with the drill-bit. Throughout the list of examples, other members of the panel chuckled in recognition, and at this last example, several panelists laughed openly.

I read a story in the newspaper about a group of young people who had been caught standing around a BBQ pit, poking a live kitten into the burning coals and laughing as the kitten cried. Who wouldn't be upset at the mental health of these individuals? But, when you think about it, the place is unimportant. Whether suffering is seen as a joke in the lab, at a conference, or at the barbeque pit, it must stop.

Cruelty doesn't have to mean being the person who pokes the kitten deeper into the coals, or being the person who wields the scalpel or syringe. It also means being the person who ignores the plight of the pain-wracked or lonely animal in the cage. Where there is acceptance of the perpetuation of wrong, there is complicity. Perhaps the Nazi doctors could not have spoken up without being shot, but we are not in that position - not any of us.

What allows this kind of jocular, cruel nonsense to go on is a lack of empathy (that undeveloped "mirror neuron") or the group acceptance of unacceptable behavior. It will continue until every one of us who cares - and we are many - gets a moral backbone, gets truly interested in real science, and speaks up, complains, refuses to accept this kind of thinking, and puts an end to it.

It's history again, isn't it? Someone gave me a book of parlor games from the Southern US. One game in it is described this way: "A distinguished lady is chosen to address the group. She must explain that a baby has been orphaned, and she will suggest that the club rise to the occasion by chipping in to raise the child for its first year. Of course, everyone will agree, and one member must be asked to volunteer to be the first to take the child home. As the volunteer comes forward, everyone claps with appreciation. Have the maid bring a swaddled baby into the room. When the lucky volunteer is handed the infant, all will howl with laughter when the cloth is pulled back and the lady finds she is holding a Negro child." The book continues: "If a Negro child is not readily available, you can achieve the same effect by using a baby pig."

We find that beyond horrific now, but it was all good fun down South in that bastion of civil liberties, the United States of America, not so long ago. And it is a great illustration of why change must keep come right on coming.

\section{The capacity for pleasure and fear}

I'm not so much condemning the people who didn't "get it" then and who don't "get it" now; rather, I'm offering it as a blunt reminder to ourselves that we are making history every day that we live and breathe. Today's conduct can be seen as future "past" horrific behavior, if you know what I mean. It was just 30 or so years ago, when I was already smoking cigarettes, that physicians in white coats appeared on TV, advising us to smoke low tar cigarettes to soothe a sore throat. It was just 30 years ago that, as Dr. Jane Goodall points out, scientists openly ridiculed the idea that chimpanzees were intelligent, had social needs, engaged in tool making and use, and had language. Or more recently, take the octopuses commonly used in laboratories:

It is only after years of electro-shock experiments on them that experimenters have conceded that these bizarre - to us - animals are so emotionally upset by their loss of control over their destiny and their inability to flee the pain meted out to them, that they commit suicide by pecking themselves to death. Jacques Cousteau first revealed how dolphins in captivity would sometimes take their own lives; now we see that behavior in other captive species, including cephalopods. Yet these animals have been treated in laboratories as if they were inanimate. Or actually, that's not so, because if they were thought to be inanimate, no one could design an experiment to hurt them and see what they would do, could they? So, people recognize that octopuses have feelings but are deliberately ignoring the fact.

Recently, an extensive study of pleasure in the animal kingdom showed that "from tickling to playing catch, animals engage in certain behaviors just for fun, even enjoying sensations that are unknown to humans." The author of the findings, published in Applied Animal Behavior Science, believes scientists,

\footnotetext{
1 "Animals just want to have fun, survey finds: From tickling to playing catch, animals do some things simply for enjoyment," Jennifer Viegas, Discovery Channel.
} 
conservationists, and others should not overlook animal joy. "The capacity for pleasure," the author writes, "means that an animal's life has intrinsic value, that is, value to the individual independent of his or her value to anyone else, including humans." And what isn't mentioned here, is that one of the most overlooked areas of animal suffering is fear. We talk about caging size and other considerations, but the "Fear Factor" isn't just an American TV game show.

This animal at this podium knows a bit about fear. My father was a very daring man, quite an adventurer who went out in fierce storms and into war zones and was at Bikini Atoll to help set up nuclear testing. He once took my mother in a jeep across the Little Rani of Kutch in India. This is an area that, at certain times of the year, is extremely dangerous, pitted with pockets of quicksand that are impossible to see but which can gobble you up. My mother only found that out, and found out that no one else had had dared accompany my father on this expedition, when they were well out in the middle of it. She remembers yelling at him and my father saying, "Oh come on, where's your spirit!" To which she replied, "At home in the drinks cabinet, but damn you, if I'd known that we might die, I'd have brought some with me."

I know what she meant, because when I was a tiny tot, he took me up a glacier many thousands of feet high. Despite the physical pain of the cold, which was intense (we didn't have polar fleece back then), what was far worse was the fear: the fear of tumbling thousands of feet down the side of that vast wall of ice, the fear that something terrible was about to happen to me. That is the experience animals in laboratories live with all the time: The mother monkey clutching her baby to her chest in her small metal box, wondering if that giant, powerful animal entering the room to take her blood is also going to steal her child. And he is, just as if he were taking a box off a shelf, ignoring her fear grimace, her desperately chattering teeth and her little begging sounds. Yet her love for her child is indisputably as strong as any human mother's love for her infant. What must her suffering be like when she cannot protect her own child? Who will speak up for her?

In a BBC documentary, scientists refer to cuttlefish as "aliens from inner space." It's a fascinating term, because, of course, our species is out there in space, spending a great deal of time, money, and effort searching for intelligent life, yet it is all around us: from those cuttlefish who communicate in waves of color (able to create a magnificent pattern on one side of his body that lures a prospective mate while creating another pattern on the other side that wards off a competitor); to the smallest desert mouse who rolls a stone in front of her burrow to collect dew; to the Indigo buntings who navigate by learning the constellations, fix their position by the height of the sun and, if blown off course, reset their paths by the phases of the moon and the rising and setting of the stars; to the rhino who communicates by altering his breathing.

And should any Cartesians be among us and laugh such things off as programming, they must also laugh off their own loves, desires, and fears, their own programmed behaviors. The Cartesians also would have to ignore studies like the one this very month reporting how five crows all were able to figure out how to use a short stick to get hold of a medium one and the medium one to reach a large one - the only one that could allow them to retrieve a food reward. All five figured it out without training, and four of the birds did it in the first try.

\section{A slippery slope is just another term for progress}

So, what if we do come across intelligent life during our space explorations? If it is stronger than we are, we will undoubtedly beg for mercy and understanding and insist that "We come in Peace." But if we find intelligent life out there that is not as strong as we are, what will happen to those noble protestations? Our governments will want to do to them what we've done to all the intelligent life forms on this planet: Capture them, cage them, dissect them, and deny them any consideration. Perhaps snack on a few of them just as we snack on the sea slug who, like a fat opera diva, so gracefully dances among the rocks, her cloak floating behind her, her mind on who knows what. But we don't have to be like that computer Pacman, gobbling up everything in our path; we can be considerate of those with less power than we have.

I hear people who want to cling to the status quo say, "Don't concede that primates need social enrichment or that rats and mice must be afforded protection, it's a slippery slope." And of course it is, but isn't a "slippery slope" that leads us away from treating others badly just another term for progress? A society can't evolve if it is afraid of the slippery slope. Looking back, it was a blink ago in time that a noted Harvard surgeon was deeply worried about the "absurd" idea that a woman might be allowed into the operating room, let alone be trained as a physician. In the time of the Suffragettes it was said that "If you give women the right to vote, you might as well give asses the right to vote." Today, we have fine female physicians and scientists and - as for women voting - well, we should be entitled to make the same mistakes at the polling booth as any man! And frankly, looking at who we elect sometimes, one wonders if asses couldn't do a better job than the lot of us.

So, what can we do? You may think that I want all animals out of the laboratories now and you'd be right. I do think it is morally indefensible - given what we know in this day and age - for us to inflict pain and suffering and fear on any other living being simply because we can. That is the lesson I take from history. And if you don't "get it," look at the animals, learn about the animals, and if you still don't "get it," look again.

However, one can still help enormously without having to embrace that belief.

\section{Regulatory testing: the obstacles and the movement forward}

I polled the PETA staff who work on these issues, asking them to give me basic starting points. I am only focusing here on regulatory and toxicity testing. Let me go through the list and I hope you will agree:

1. Where there is a non-animal alternative, use it.

2.Don't automatically default to animal testing: profiling a chemical's biological activity using a suite of non-animal methods will allow for thoughtful toxicology by identifying 
the most hazardous chemicals and providing information that can guide further testing and, of course, NO experiment using animals should EVER be carried out if the information is available or can be derived elsewhere.

3. Where there isn't an alternative yet, work to find one and keep an eye on what's going to be available soon.

Alternatives for many biological endpoints are in sight, and for the more complex endpoints in the areas of toxicokinetics, chronic toxicity, and carcinogenicity, there are efforts that urgently need promoting, including PETA's planned workshop focusing on replacing the rodent cancer bioassay.

4. The EPA and NIH are beginning to act on the vision set forth in 2007 by the National Academy of Sciences, which recognizes that the near-exclusive reliance on animal testing that has characterized chemical testing programs to date are costly, time-consuming, and not up to the task of accurately and adequately assessing the toxicity of tens of thousands of chemicals. Both the NAS report and the 2009 EPA strategic plan recommend moving away from dependence on animal tests to a process that relies more heavily on in vitro assays to predict human health effects.

EPA and NIH have created formal collaborations to develop and implement this approach, such as the ToxCast and Tox 21 initiatives.

It is encouraging to note that federal agencies and some industry consortia are stepping up to the plate to help fund these initiatives, in addition to PETA which, up till now has tried to step into the void by providing massive donations to in vitro laboratories and QSAR experts, even though our budget is mere manicure money to federal agencies such as the EPA.

May I solicit your support to encourage and fund the use of these technologies in current and future testing programs? There is still so much work to be done as current testing programs have been slow to incorporate this new approach.

For example, there is the hideous mess that is the EPA's Endocrine Disruptor Screening Program. The first phase could kill more than 40,000 animals - and not one of them will die quickly or painlessly - to test just 67 chemicals, all of which are either pesticides or High Production Volume chemicals that have already been heavily tested. The additional testing is highly unlikely to provide any useful information for additional regulation of these chemicals, especially when the EPA still can't say how it is going to use the resulting information! This program is so out of tune with where we are now that it is like designing an iPhone app using carrier pigeons. This program needs to be redesigned from the bottom up to take advantage of the latest technology and new approaches. Please take a look at our poster, number 539, that describes an integrated approach to endocrine testing and see how you can use it.

The US National Toxicology Program continues to kill thousands of animals every year to test well characterized chemicals, even natural substances such as ginseng and green tea, and it does so if the substance is nominated by anyone, even by a single anonymous person.

And what of ICCVAM? In a decade, ICCVAM has gone from beloved baby to Frankenstein monster. Instead of doing the job the US Congress intended it to do - namely to facilitate the incorporation of non-animal methods into government regulatory programs - it has become the chief obstacle in the US to the use of non-animal testing methods.

Recently, ICCVAM rejected the work of a consortium of companies that worked together to develop a non-animal method for assessing eye irritation. The work was so promising that the EPA launched its own pilot program, accepting data using this method. So, now the EPA is making more progress than the federal entity whose job it is to do so.

Another shameful example is that nine years ago, an international workshop concluded that in vitro cytotoxicity could be used immediately as a dose setting measure to reduce the number of animals poisoned in lethal dose tests. The experts also concluded that, with interest and funds, the test could be validated as a complete replacement method for lethal dose tests within 2-3 years. Yet it took until 2008 for ICCVAM to issue formal recommendations to agencies to use the cytotox method and then only as a reduction method to set the starting dose for poisoning animals.

NIEHS has not made appropriate funding of ICCVAM a priority, and ICCVAM does not do the sort of independent research performed by ECVAM and ZEBET. It appears that ICCVAM members, who are drawn from the federal agencies, are being allowed to misuse ICCVAM to perpetuate their antiquated biases in favor of animal tests. This is evident through ICCVAM's continued presumption that animal tests are the "gold standard" of toxicology to which all non-animal assays must measure up (or down as the case may be) and through emails leaked to PETA in which ICCVAM representatives discuss circling the wagons against evidence-based toxicology. It should therefore come as no surprise that the US lags so far behind Europe and some other countries, not only in real football but in implementing non-animal testing methods too. We documented that disgrace in an extensive report last year that ended up on the front pages of the Washington Post.

5. The current US toxic chemicals legislation, the Toxic Substances Control Act, is about to be revised. While this is sure to lead to requirements for information similar to REACH in the EU, it also provides an unprecedented opportunity to incorporate these new approaches and new technology into toxics legislation - something we at PETA are working hard to do and which you will hear about in the next session on chemicals and pesticides.

6. In Europe, there is much work to be done as well. In spite of the deadlines imposed by the Cosmetics Directive to eliminate animal testing and a number of EU initiatives, there are still no accepted alternatives for eye irritation nor any completely non-animal methods for acute toxicity, and non-animal replacements for chronic and developmental toxicity will not be in place for the 2013 deadline. REACH will have an enormous impact on the number of animals used in testing. There are some animal reduction provisions in $\mathrm{REACH}$, but with thousands of chemicals requiring base data sets by 2010 , there will be animal suffering on an unprecedented scale.

Even without REACH yet in full swing, the numbers of animals used in the UK has risen every year since 2000, with 
a dramatic increase of $42 \%$ in the past decade. Most of this is due to the increasing use of transgenic mice - with thousands of them being used to breed and maintain each line even though these so-called "models" of human disease are of questionable relevance. And in spite of public support for a ban on primate experiments, the use of primates in the UK actually rose 16\% in 2008 over 2007. Surely, intelligent and dedicated people can find a way to reverse this trend.

While the continuing revision of Directive 86/609 provides an opportunity to address long-standing problems with the use of animals in European experiments, there is a worrisome de-regulatory agenda that threatens to gut the proposal of its most progressive measures. Europe must not miss the opportunity to put in place a rigorous and comprehensive system of regulation that reduces animal suffering; fosters the development, validation, regulatory acceptance, and uptake of replacement methods; and, most importantly, provides the basis on which meaningful progress will be made towards the goal of eliminating all animal experiments as soon as possible.

That is the end of the list.

\section{Passing the final exam in the history of mankind}

One good thing that came out of the 1960s, and I'm not talking about tie-dye, was the expression, "If you aren't part of the solution, you are part of the problem." Society is deeply indebted to each of you who are part of the solution. Those of you who are in government, it is vital to rock the boat; those of you who are on committees and in funding agencies who opine that animal tests are not only ethically flawed but often conducted out of habit, obstinacy, laziness, and because no one has spoken up, thank you for living.

Now, let me return to where I started. If we believe what social scientists have told us - that ordinary humans are capable of extraordinary cruelty - we must recognize that laboratories are exactly the place where such things will occur. It is not enough to regulate vigorously, although we must do at least that. As a group, human beings are far too tolerant of cruelty and far too unpredictable to be entrusted with the lives of truly vulnerable beings, yet we are in that position and must be vigilant about our conduct.

And finally, if you are thinking, "What was that bit about Brueghel's Two Monkeys?" - it refers to the poem by Wislawa Szymborska, who wrote:

This is what I see in my dreams about final exams;

Two monkeys, chained to the floor, sit on the windowsill,

The sky behind them flutters,

The sea is taking a bath.

The Exam is the History of Mankind

I stammer and hedge.

One monkey stares and listens with mocking disdain,

The other seems to be dreaming away -
But when it's clear I don't know what to say

He prompts me with a gentle

Clinking of his chain.

The animals are all around us, intelligence and emotions shining from their eyes. They are prompting us - with the clinking of their chains - to lead a life we will be proud of when the time comes, as it always does to mortal beings, to take that final exam.

No one knows when that will be, but a time will come to all of us - those of us who answer to a god and those of us who answer to ourselves - when we look back on our careers and our lives with pride or with regret.

Society's ethical values expand as we come to understand that we not only have the capacity but are duty-bound to extend consideration beyond just ourselves, our families, our races, and, without a doubt, our species. To understand, as Dr. Albert Schweitzer said, "Ethics are complete, profound and alive only when addressed to all living beings."

To put it in practical perspective, I was in England recently and, as I was reading the Sunday paper, I came across a column written about dogs. The columnist wrote: "Contrary to what Buddhists would have you believe, remember, a dog is just a dog: he will never write a great book or compose a great symphony." I thought "Hang on a minute!" I'm going to bet that this columnist will never write a great book or compose a great symphony, and one thing I know is that he will never detect a cancerous tumor with his nose, and he certainly wouldn't be able to find his way home over hundreds of miles without the benefit of a GPS, a map, a street sign or advice from another human being. Perhaps what separates humans from other animals is the desperate quest that our species has to find something that distinguishes us from the other animals.

Maybe the question should be "When will we all start seeing ourselves as just one of the many musicians in this vast orchestra of life, one no more special than the others?"

When we take those final exams, may we all be able write that we contributed to the History of Mankind by bravely confronting our biases and by helping our species evolve from undisciplined bully to compassionate citizen. May we be able to say that each of us had the nerve, the backbone, the principle, and the vision to say what needs to be said about the use of animals, the suffering of animals, and the appropriateness of the behavior of those around us. I wish you all the best in everything you do to pass that exam.

\section{Correspondence to}

Ingrid E. Newkirk, President

People for the Ethical Treatment of Animals

501 Front Street

Norfolk, VA 23510

USA

e-mail: jessicas@peta.org 